\title{
十年来的綜 合考察
}

\author{
筑可楨 \\ (中国科学院副院长中国科学院紵合考察委員会主任)
}

\section{-}

我国幅員广闊，有着优越的自然条件和丰富的自 然資源，但是牛殖民地牛封建的旧中国遺留給我們的 有关科学瓷料却极为算乏，占全国总面积百分之六十 以上的边荒地区，在科学上几乎还是一个空白地区。 解放后国家經过短时的恢复时期，立師开始了大規模 的經济建設。社会主义的經济建設需要按昭有計划按 比例发展的法則进行。計划經济是社会主义經济的主 要特征。国民經济建設按国家編制数年的和年度的經 济計划进行。国民經济的发展不仅謷有飞快的速 度， 而月各种资源的开发利用应該是全面的、綜 合的、合 理的。要使这些优越的条件和富饒的資源能够适合国 家計划楥济的要求，得到充分的利用和合理的 开发， 就必須对于需辢开发的地区进行一䒺列专业的和綜合 的調查研究工作，以便在充分掌握自然条件的变化規 律、自然資淙的分布情况及社会經济的历史演变过程 等資料的基础上，提出利用和开发的方向、国民經济

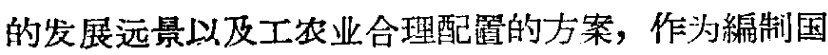
民經济計划的科学依据, 使国民經济計划既有长远的 展望又有可靠的基础。

綜合考察是为了达到上述目的而进行的一种科学 工作。它根据国家提出的任务和地理資源的特点, 組 織各种必要的学科，其中如地稹、水能，地理、土壤、 植物等学科和工、农、林、牧、交通、經济等等方面共 同参加工作。不但姴有自然科学方面的也要有社会科 学方面的学科,它所考虑問題的着眼点与某一学科、某 一专业或某一部門不同，它須从各个角度分析、考虑， 多方面比較論証，提出多种方案，选择取捨，尽量达 到比較綜合、全面和合理，避免片面性和盲目性。它 的工作方法是一个地区的考察中，抓着关鍵性的重大 的問題深入研究，以解决这些间題为中心，考虑全面 仰局，因此是点面結合，以点带面。經过綜合考察最 后提出的报告是远景的建議性的方案，供国家計划部 門編制国民經济計划时的参考。因此有人形象化地 形容它是“計划的計划”, 对于計划起着“探照灯的作
用”。

綜合考察工作的总方向虽然应当着重于长沅目标 而不应当单純从解决眼前的具体問題出发, 但是在我 国的具体情况下，不能把远景和当前生产建設截然分 开，当前的重大建設計划慗与远景的展望相結合，而 远景的規划有許多方面又需要現在垖着手进 行。同 时我国經济建設的計划和規划是由中央統一領导和 地方分权管理相結合而制定的，国家任务与地方任 务二者㨁接互相关联着。因此我国的綜合考察在工作 过程中对于与国家远景有关的地方任务也应該积极考 虑。耻外某些国家的重大的改造自然的工作也是綜合 洘察的重要工作內容。

另外，現在的考察工作，較多的是雀中在靠近边疆 待开发地区，从直接考察收集資料入手，发現問題进 行深入重点的研究，这是完全必要的，但今后对某些 重大問題，从現有材料的基础上，組織有关較高級的 科学人員非行研究和解决也是綜合考察工作任务之 -。

解放以后較大規模地进行綜合考察工作, 开始于 1951 年由中央文敎委員会委托中国科学院組織的西 藏考察队。它对于西藏进行了地质、地理、气象、水 利、农业、牧业、植物、士壤、社会、历史、語言、文艺、 医䓎卫生等各个学科的初步考察工作。該項考察在 1954 年暫告一段落。1951 年我国进行抗美援朝以后， 美帝实行封鎖政策，对我国禁运橡胶等物資，为了热 带資源植物的种植和发展, 自 1952 年以来进行了海 南鳥、霄州牛島和广西南部的考察, 抖在此基础上于 1957 年建立了固 定的柎关华南热带生物㗄源的綜合 考察的队伍。1955 年 由苏联科学院的建議, 步同組 織了紫胶的考察工作，后来发展为云南热带生物资源 綜合考察队。1956 年中国 科学院 成立了綜合考察委 員会，統一組織和領导中国科学院有关的綜合考察工 作。同年科学規划委員会制定 12 年国家科学 技 术发 展远景規划網耍后, 由中国科学院綜合考察委員会担 
负有关“自然条件及自然资源”的綜合考察部份。1956 年 8 月又部立了中苏两国共同調查黑龙江流域自然資 源的协定。几年来由中国科学院綜合考察委員会直接 組織的考察队前后共計有以下十个:

（1）橫河中游水土保持綜合考察队。任务是根治 黃河水害和开发黃河水利, 为提高农业生产汼对減輕 三阴峽水庫的泥沙汘积, 对于黃士高原地区的水土流 头間題, 进行科学調查研究工作。1953 年开始工作,

已在 1958 年結束調查工作。

（2）黑龙江綜合考察队。任务是进行黑龙江流域 的水能、水利、地稹、矿产、农、林、牧、漁等自然 资源和自然条件、經济情况的綜合考察抹提出开发远 景方案。1956 年开始工作，1959年結束野外工作， 1960 年做出考察地区的开发方案。

（3）新疆綜合考察队。任务是以农、林、牧、水 利为中心的自然条件和自然資源合理利用及生产力配 直的研究。1956 年开始工作, 主要的野外考察工作 預定在 1959 年告一段落，1960 年进行全面的科学总 粘。

（4）云南热带生物資源綜合考察队。任务是在紫 胶孝察的基础上扩大为云南热带亚热带生物資源的綜 合开发和利用。1955 年开始进行考察, 預期 1962 年 可告結束。

（5）华南热带生物資源綜合考察队。任务是在广 东、广西、閩南地区进行热带和亚热带生物資源的綜 合开发和利用的考察和研究, 扗特別注意配合橡胶和 咖啡等热带經济作物的种植。1957 年 开始 工作, 預 期 1962 年可告結束。

（6）土堆調查队。任务是配合流域規划需要，进 行黄河和长江灌区的土境調查工作, 讲进行一定的定 位試驗工作。1956 年 开始工作,現仍在継續工作中。

（7）盐湖科学調查队。任务是考察柴达木岎地盐 湖资源, 研究綜合开发利用。1957 年开始工作，現 仍在継續工作中。

（8）青甘綜合考察队。任务是考察青甘地区工业 和农业資源, 研究綜合开发利用和生产力配置問題。 1958 年开始工作，預期 1961 年可告結束。

（9）治沙队。任务是根据 1958 年 10 月西北六 省、区治沙规划会議上制定的治沙规划方案, 进行沙 漠改造利用的科学考察工作和試驗研究工作。1959 年 开始組成。

(10)西部地区南水北調綜合考察队。任务是根据 1959 年 2 月水利电力部和中国科学院共 同召集的西 部地区南水北調考察规划会議的决定，进行引水路綫
及該地区走源綜合开发利用的綜合考察工作。1959 年 开始組成。

以上十个考察队的考察, 范围几乎漏及全国。其 中多数是科学资料缺乏, 交通不便, 供应困难的地 区。

参加工作的科学人員, 除中国科学院及.其分院的 研究机构成員外，还有中央和地方产业部阴，以及各 高等学校的人員, 参加的全体人数如以 1958 年八个 队为例, 共 1,500 人左右, 1959 年还将增加治沙队和 南水北調队的工作人員, 預計全体人員 将超过 2000 人以上。

此外还得到苏联的无私帮助, 多数考察队都有苏 联科学家参加工作, 以 1958 年为例, 共有苏联高敉 科学家和輔助人㬝 100 余人参加工作。

除由綜合考察委員会所組織的考察工作外, 佁有 中国科学院各研究所或其他单位組織的考察工作。如 海洋綜合調查也是綜合性的規模较大的調 查研 究工 作。它的任务是获取中国海洋情况的基本資料，繪制务 类海洋图集, 經过分析研究从而制定中国海洋开发和 利用方案。1958 年 9 月起在中国科学技术委員会（簡 称科委)海洋組的統一領导下，动員了全国各单位的 海洋研究技术人員和仪器設备、船只等, 在全国海洋 同时开展調查工作。还有各种地质考察队、高山冰雪 利用研究队等, 不-D.列举。

$\equiv$

解放以来我国綜合考察工作涉及的地域辽闊, 包 括的学科繁多, 工作规模相当大, 所取得的成果也是 多方面的。首先是对于考察地区的自然条件、自然凅 源及社会經济的基本情况有了較全面的了解。其次, 对. 一些重点地区和問題还进行了較为深入的綜 合. 研 究, 从而向国家和地方提出了一些和生产建設密切有 关的建議和方案。此外在工作过程中积累了丰富的科 学資料, 学科的理論永平亦有一定的提高。同时还摸 索了一套在中国具体情况下如何組織綜合考察工作的 基本方法和經驗。

現就主要方面說明如下:

解放以前我国科学工作者对于海洋的調查只进行 了极为零碎的工作, 解放后海洋調查有了大踏步的发 展, 特別在 1956 年制訂了十二年科学规划以后, 迅速而有計划地开展起来。經过数年来的海洋綜合调 查, 已初步測定了关于海洋自然条件的基本資料，例 如渤海、黃海、东海主要地区的潮汐, 海流, 海 水化 学, 海底的現代沉积, 海洋生物（包括浮游生物及底 
棲生物) 等方面的資料。在烟台鮐魚漁埸、黃河口小 黃花魚漁場、辽东湾毛虾漁場及其他漁場的調查中都 获得了初步結果, 这些結果对于指导漁业有着重要的 意义。由于我国是港湾和浅海发达的国家, 在 渤 海 湾、胶州湾、长江口、杭州湾, 以及各地已进行的灌 涂調查工作，对于进一步发展水产、盐业、潮汐发 电、农田水利、航运等方面都将发揮作用。

在西藏高原的初步調查中!已經知道該区矿产資源 是非常丰富的。矿产的种类极多，已发現的就有鉄、鉻、 銅、鉛、锌、鎮、磁、硫、重晶石、刚玉、紅柱 石、石榴子石、滑石、㿝石、石墨、石高、煤、油頁 岩及盐类資源等等。考察队提出了今后应进一步深入 調查的綫索。西藏的水利資源地很丰宾。雅盒藏布汇. 流量稳定, 在某些地段落差大, 峽谷长(如曲水以西, 泽当以东，則拉宗以东等地)独藏着互大的水利資源。 考察队对于西藏的森林資源, 畜牧資源及生物資源(䓎 用植物及皮毛兽等) 也初步掌握了概略的情况, 抹在 工作期間引种了西藏地区过去没有种过的蔬荣，如番 茄、甘蓝、黄瓜、南瓜等, 生长都很良好。此外还引 种了各种粮食作物亦获得了良好結果。

黑龙江队对黑龙江流域的水能水利資源，不仅查 明了中上游的流量, 而且对中上游梯級开发埧址、地 稹、水文作了比較詳細的勘察, 上中游共䍸察七个埧 址, 将可作为五个梯級来开发对第一期工程可能施工 的埧址, 进行了詳細的地稹鉆探工作与比較方案的研 究。1959 年度将提出一个电站开发的技术經济設 計 报告, 以供国家在决定黑龙江流域电力开发計划时作 依据。此外, 还对大小兴安岭和烏苏里江等地区的地 稹矿藏进行路普查, 繪制了上述地区的五十万分之 一的地稹图和大地构造图, 研究了成矿规律, 扑提出 了找矿的方向, 編制了內生成矿图和外生成矿图。找 出鉄、锃、銅、鉛、锑、鵭、螢石、禾、石油、 油頁岩等矿产及矿化点。有些地点已由地方, 或由地 稹部門作进一步的鉆探。其他如森林、土壤、植物、漁 业等资源以及交通运輸和社会經济等各个方面, 也进 行了解和教察, 对各种自然条件也收集了資料, 逐年 加以整理和充实, 将在 1959 年野外工作結束后編写 关于黑龙江流域的全面的綜合开发远景方案, 提供国 家經济建設部門和計划部門作为制定計划的俵据。

声甘队虽在去年才开始工作，但已对月洮工程的 埧址和渠道的一部分工程地盾給予了㨁接的帮助, 对 河西走瑯提出了全面的生产力配置的初步意見。抹且 对北大河流域的水士資源提出了合理利用的規划意見 等。
柴达木盐湖队不仅对盐湖的情况和某些资源的开 发提出了意見，而且直接帮助地方解决有关国家急需 的鉀肥的土法生产的技术問題。柴达木盐湖盐类的丰 富，不仅是中国，而且在世界上也是少有的。1957 1958 年盐湖队在这个区域进行了調查, 初步掌握了盐. 类資源分布和成分等各种資源材料，說明这个盆地不 仅有基本化学工业原料所需的食盐儲量非常巨大，而 且富有工业和各种新技术上所急需的化学原料和农业 生产上非常需要的鉀。盐湖附近的地层中也发現沉积 着各种盐类。継續深入的研究有发現更多資源的可 能。就发現的重嫯資䝠研究其綜合开发利用的方案和 工艺流程亦在开始。柴达木永地很可能是我国化学工 业的极其垂要的基地之一。

新疆队在过去三年的考察中，对北疆瑪約斯河地 区提出棉粮比重等农业生产配置沅景的意見, 已为当

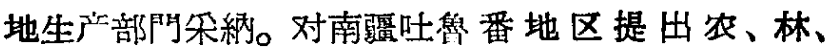
牧、水利的綜合开发建議，作为规划的重要参考。焉 耆地区开都河改道問題，为琵幂(地少水多)、庫尔勒 (地多水少)地区农业发展的关鍵性問題之一。由于卙 河流入博斯騰湖蒸发損失极大，每年蒸发損耗共达 10 -16 亿公方之多, 需要使其改道直接經过孔住河流到 庫尔勒、尉錅等地区，作为灌溉之用。但要实現开都 河的改道讲綜合利用其水利資源，需解决上游发电和 中、下游地区溜溉用水之間的矛盾，水量在时間的分 配上获得合理調节等問題。該队在新疆水利厅已有 料的基础上进行考察，扭提出了兴建水庫窣的解决办 法。該队讲进行了北疆額尔齐斯河、烏倫古河、瑪納 斯河、伊棃河以及南疆的孔雀河、塔里木河等河的調 查，对水利資源作了新的估計，扭对地下水的情况，进 行了广泛的調查和研究。对于新疆干旱地区的水文地 稹，士壤，植物，农牧等方面都掌握了丰富的資料。 此外在土壤工作方面为新疆生产兵团盐清士改良进行 了排灌試驗。

黃河队在考察过程中，根据所掌握的自然 条 件、 經济情况和水土流失特点, 在黄河中游黃土高原地区 共 35 万平方公里的土地面积上进行了考察。制定了 自然区划，农业区划，經济区划。水土保持士地合理 利用区划提供了农林牧綜合开发和水士保持措施合理 配置的科学依据。同时編制了在推广工作中一般干部 及掌众都能使用的“水土保持手册”。此外还根据不同 区域的水土流失类型，結合垶众的生产需要先后进行 了十一个小流域的重点深入調查研究，扵分别制訂了 水土保持士地合理利用綜合措施配圈規划。

固沙队 (最初是黃河队的一部分) 三年来对內蒙、 
陕西、宁曼、甘为等省区的沙漠进行了初步考察，为 今后开展治沙工作提供了部分科学资料。

土境調查队在黃河中下游及长江中游地区进行了 广大的灌区調盗。已調查的面积,黃河流域为 27.6 万 平方公里, 长江流域为 18.9 万平方公里, 分別制出 了20 万分之一及 10 万分之一土壤图, 不仅㴖足了橫 河长江流域規划的需要，而且值接帮助了一部分人民 公社进行了土㙲改良规划。在华北，內蒙，宁夏等地 結合地下水进行了土堛盐化的研究，明了各种不同 的盐清化类型，抹提出了预防盐漬化的意見。

我国幅員辽閵，气候寁具热带亚热带、溫带和寒 溫带性稹，生物资源极为丰富。特別是热带生物資 源，在社会主义陣营中占有重要地位。1952年开始有 了一千多位科学技术人員响应政府号召在海南鳥和奥 西进行了广泛的調查，对于橡胶宜林地的选择起了重 大作用。其后 (1954-1956) 中国科学院有关的研 究 所, 和林业部門的研究所以及几个大学所組織的綜合 考察队进行了較深入的工作，对于建立防护林带及萌 生带提出了具体意見; 了解了气候因素对植物的影 响，以及寒潮对植物生理学上的作用，提出了防寒的 各种措施; 土裂学家改进施肥方法的建議，节約了大 国国家资全。1958 年华南队在考察广西十万大山地区 的过程中摸清了䀭地区的自然条件，抌制定了該地区 的十九个县的自然区划及六个县的經济区划。在該区 找出大面积胶林地，抖找到有經济价值的植物 537 种，有桱济价值的动物 130 种，已提出其中特別 应㚊重視的种类。根据不同的自然情况，对于荒山、 热坡提出了相适应的綜合利用方式和适宜的造 林树 种，或先鋒树种。

云南队对于紫胶进行了全面的調查。紫胶是云南 特有的产物。在 33 个县的 120 种寄主植物上采集到 然胶, 查明了胶蚧科的种类、产区、寄主、天敌, 而 且还进行了定位試驗研究, 唔訓技术力量, 指导营众生 产和推广。彭队久在云南西双版納区做了重点調查, 抹与全省的植物資獂普查相結合，掌握了大量的資料。 我国高等植物种类共約三万种, 而云南一地就占全国 的 $48 \%$ 左右。数年来調查了一千多种資源植物，大多 数都进行了野外分析。其中經济价值較大, 有发展前 途的种类茲多。云南的地势虽然不如两广平坦开闊， 但由于冬季没有寒流, 秋季没有盛风的威胁, 春季虽 旱, 但有大量露水, 足以滋潤, 对于发展热带生物盗 源具有有利的气候条件。

参加考察的各个学科一般都收集了各个方面的資 料扵繪制了图件，如地貌、土壤、植被、水交等的一百
万分之一和五十万分之一的比例尺图, 和重点地区的 二十万分之一的比例尺图；抹进行了各个考察地区的 自然区划工作；地稹及水文地稹在个別地区也繪制了 区域地盾图和水文地稹图; 抹收集了数以万計的动 物、昆虫、植物、土壤等标本, 还发現了許多新种昡 稀有种类，这些資料对划分全国自然区划和区采工作 提供了有利的条件。

通过考察工作，对于自然条件也有了很多新发 現, 推翻了某些陈旧的概念, 茜至㹨得了新的解决自 然規律的綫索和途径，从而郬助了科学的提高。

过去士壤学家对华北平原的土壤簡单 地 統称为 “沖积土”, 这只能反映地稹沉积作用, 而不能反映农业 生产特性及土域的发生演变情况。土壤队在考察中运 用了土壤发生学的理論, 查明了各种土壤的过渡演变 情况，抖詳細地划分了土类和变种。过去对亚热带北 部地区与暖溫带土壤(褐土) 如何过渡何不很明确。通 过考察工作，知渞亚热带北部地区主要为黄棕壤 (亦 有称为黄褐土)，分们于长江以北的地区、唐白河 谷及汉江以北地区。对于南方水稻土壤的文生演变, 也有了进一步的看法。在东北、青海、甘肃及新疆的 土壤考察中初步拟定了土壤分种系統，說明了土壤类 型分乕及其特征。新疆方面肯定灰棕色浣漠士为北疆 的地带性土埕。在东北地区的松嫩平原的南部发現苏 打盐上的形成与含油地层中含盐地下水承压影响而上 升的作用有关。对于我国热带亚热带地区士境有了进 一步的詮識, 但仍需梁入研究。

地质学家在黑龙江流域地区綜合分析了況积厚度 和岩相变化, 折緆和断裂情况, 岩浆活动, 变盾作用 以及矿产分乕特征，初步訓識了末区的地盾发生历 史，将該区大地构造区分为 6 个带，指出相应地区矿 产远景; 在柴达木盆地发現大量釷盐沉积, 說明了內陸 性湖泊和鉀盐沉积的关系; 在广西二迭紀地层发現較 大量的原生菱鉄矿，都为今后开拓了新的找矿方向。

地貌学家在考察过程中了解到新疆塔里木河沉积 速度大, 河朱极不稳定, 河流改滂的結果和过去学者 所发表的論文以及現行的地理数科书所說大为不同， 經过考察提出了修正, 扭对河流变迁的原因作了进一 步的分析。在新疆考察过程中，知道了天山高山带厂 泛分瓜着遭受古冰川强烈作用的冰川地形, 但在天山 中段西部却明确可分四个时期。在云南考察中, 地盾 地貌工作者研究了风化壳型的䤼矿的富集与微地貌条 件的关系。对于云南地貌的研究, 过去只从形态上䚯 識, 而忽略了地貌的发有, 經过調查, 特別是在海找 1350 公尺的大渡崗(思茅以南)一带的高原面上, 发現 
无可怀疑的河流相沉积，有力地泼明了云南高原汋过 去长期剥玲所形成，到第三紀末和第四紀初期的地壳 运动, 上升至現有高度。

气候学家考察了东北、新疆、华南地区，抹与土 壤学家, 地植物学家交換意見后, 对于我国划分热带 亚热带、溫带和寒溫带的分界綫，有了进一步的䚯 識。过去有些学者, 主张在亚洲东部以夏天赤道季风 能达到之界限为热带的北界, 以夏天热带季风能达到 之界限为亚热带的北界, 如绍此分法我国的亚热带将 包括东北的黑龙江省南端及內蒙新疆自治区的大部， 这与实际情况相差很远，經过实地考察，訩为我国亚 热带的指标以积溫 $4500-8000^{\circ} \mathrm{C}$, 最冷月气溫 2$16^{\circ} \mathrm{C}$, 无霜期自 $240 \sim 365$ 天为相宜, 贸此指标我国亚 热带的北界大致接近于北緯 $34^{\circ}$, 亦郎淮河秦岭白龙 江稙至东径 $104^{\circ}$, 这条綫再向西已属高山气候带。 这与农业生产上一年两熟的北界大致相符。新疆虽有 部分地区全年积溫計可超过 $5000^{\circ} \mathrm{C}$ (如和閶、吐鲁番) 或在夏季佾可栽植一年生的亚热带作物，如棉花等， 但終因冬季溫度太低，常至摄氏零下十度，多年生亚 热带植物均不能自然地在露地过冬，故不应列入亚热 带。在广西調查中也提出了关于划分热带亚热带的意 見。

植物学家証明丁北疆准噶尔为土耳其斯坦荒漠和 亚洲中部荒漠的过渡地带, 扵提出其西部分界綫位于 准噶尔西部的界山。在云南植物区采的起源方面則提 出了新的見解。

\section{四}

取得以上衫步成績的原因是多方面的, 但首先是 由于党的領导和重悓。1956年国务院科学规划委員会 制定了十二年科学远景規划, 給綜合考察工作提出了 任务和方向，1958年党中央提出睡設社会主义的总路 綫，更使綜合教察工作进一步明确了科学工作为国家 建設服务的精神, 实行政治掛贬和任务带动学科的工 作方法, 使我們工作取得更大的成績和更快的发展。 几年来的工作使我們深切地体会到綜合考察工作只有 积极地配合和围繞国家的重要中心任务才能使工作得 到順利的进行; 才能得到有关方面的密切配合。因此
在制定考察工作的計划时亦需以如何有效地来完成中 心任务为出发点, 对各学科提出要求。在考察方法上 应强調点面有机地相結合, 通过面的广泛活动来了解 情况, 发掘問題, 通过点的深入研究来解决問题, 取 得經驗。

其次是由于各級地方党政指导和广大辢众的专 持，我們进行綜合考察工作虽为国家长沅的重大的任 务进行工作，但是在具体計划和步驟的安排上，情况 的介紹、資料的收集上，地方科学力量的配合上以及 在工作条件和物資供应的保证上都要依掌地方党政的 指导和支持，翌众中有丰富的生产上的各种經驗，我 們訩真学习和汶取,加以提高, 对我們的工作有很大的 意义。而我們工作中和工作后所取得的成果, 也需要 及时向地方党政量报，一方面供其参考，另一方面更 重要的是使我們的成果根据他們的意見加以修改和补 充，使更符合实际，抹进一步在实践过程中加以检查 和驗証。

参加工作的各有关单位发揮去产主义大协作精神 也是工作取得成績的原因之一。綜合考察工作的范围 大，学科多，任务重，单靠少数人員力量是无法完成 的。几年来考察工作除了科学院所属单位的人員积极 参加外，还訨靠了高等院校、产业部門等有关单位的 通力合作，扭經过参加工作的同志們的辛勤劳动, 策壁力, 才能圆滿地完成了任务。

最后, 我国科学力量較为薄弱, 綜合考察工作更 是如此，而且缺乏經驗。但我們及时地得到苏联科学 院及苏联其他部門的大力帮助，特別是对綜合考察工 作富有經驗的許多苏联科学家，来到我国极为艰苦荒 僻的地区从事工作，不少重大的問題都是由于他們的 指导才获得解决，他們对于我国建立棕合孝察工作起 了很大的作用。他們汼热情的培养我們年青的科学工 作者，这种共产主义的风格，是值得們我哀心 感 激 的，这些动人的事蹟亦将在我国的綜合考察工作史上 写下光輝的一頁。

建国十年来，綜合考察工作有了大踏步的进展， 取得了一定的成就，但是我們的队伍和工作水平还远 远不能适应国家的需要，我們应不断地改进工作，以 期在社会主义建設中发揮更大的作用。 